\title{
RANCANGAN TEKNIK PENYEDIAAN AIR BERSIH IBU KOTA KECAMATAN MANDOR KABUPATEN LANDAK
}

Erland Evansta Sulisuka ${ }^{1}$ Laili Fitria $^{1}$ Ulli Kadaria ${ }^{1}$

1 Program Studi Teknik Lingkungan Jurusan Teknik Sipil Fakultas Teknik Universitas Tanjungpura, Pontianak Email: erlandevansta11@gmail.com

\section{ABSTRAK}

Sumber mata air Bukit Godang merupakan salah satu sumber mata air yang memiliki potensi untuk dikembangkan menjadi sumber air baku di Kecamatan Mandor. Penelitian yang dilakukan meliputi; proyeksi kebutuhan air penduduk Kecamatan Mandor hingga tahun 2037, analisis kualitas air sumber air baku yang ditinjau, analisis kuantitas dan kontinuitas air baku, serta pembuatan rencana desain jaringan pipa transmisi, bangunan penangkap mata air, dan reservoir. Hasil proyeksi penduduk pada tahun 2037 adalah 11.881 jiwa. Dari hasil analisis diketahui bahwa sumber air Bukit Godang layak dikembangkan sebagai sumber air baku. Hasil analisis debit andalan 99\% dengan menggunakan Metode Mock adalah 42,78 liter/detik, besarnya debit ini masih dapat memenuhi kebutuhan air penduduk sampai dengan tahun 2037 yang besarnya 5,16 liter/detik, Hasil analisis terhadap uji kualitas air memenuhi kelas mutu air kelas 1 berdasarkan PPRI 82 tahun 2001. Hasil analisis rencana jaringan pipa menggunakan EPANET 2.0, dapat diketahui bahwa sistem pengaliran secara gravitasi, panjang pipa $2.230 \mathrm{~m}$, velocity 1,5 meter/detik dan tekanan rata-rata adalah $12,82 \mathrm{~m}$. Dalam penelitian ini juga dilakukan perencanaan bangunan penangkap mata air / broncaptering yang terletak pada titik kordinat $0020^{\prime 2} 21,9^{\prime \prime}$ LU, $109^{0} 18^{\prime} 17,8^{\prime \prime}$ BT. Reservoir terletak didesa Salatiga dengan kapasitas 326 m³ $^{3}$.

Kata Kunci: Air baku, debit andalan, kebutuhan air.

\begin{abstract}
Bukit Godang is one of the springs that have the potential to be developed into a source of raw water in the District of Mandor. Research conducted include; projection of water needs of the population of Mandor until 2037, analysis of water quality of raw water resources reviewed, quantity analysis and continuity of raw water, and design of transmission pipelines, springs, and reservoirs design. The projected population in 2037 is 11,881 inhabitants. From the results of the analysis is known that the water source Bukit Godang feasible developed as a source of raw water. The result of 99\% mainstay debit analysis using Mock method is 42,78 liter / second, the amount of this discharge still can fulfill requirement of water of population until year 2037 which amount 5,16 liter / second. Result of analysis to test water quality fulfill class of water quality class 1 based on PPRI 82 year 2001. The result of pipe network plan analysis using EPANET 2.0, it can be seen that gravity drainage system, pipe length 2,230 m, velocity 1.5 meter / second, and average pressure is $12,82 \mathrm{~m}$. In this research, there is also planning of building of broncaptering located at coordinate point $0^{\circ} 20^{\prime} 21,9^{\prime \prime} \mathrm{LU}, 109^{\circ} 18^{\prime} 17,8^{\prime \prime}$ BT. Reservoir is located in Salatiga village with a capacity of $326 \mathrm{~m}^{3}$
\end{abstract}

Keywords: Water Resources, dependable discharge, water needs.

\section{PENDAHULUAN}

Pembangunan Kabupaten Landak khususnya Penyediaan Air Baku, memerlukan terobosan-terobosan dalam upaya pemenuhan kebutuhan dasar yang menguasai hajat hidup orang banyak, misalnya dengan membuat sistem instalasi pengolahan air sederhana (SiPAS). Unit-unit pelayanan dan distribusi PDAM yang ada di Kabupaten Landak belum bisa dinikmati penduduk secara optimal. Hal ini disebabkan karena jaringan pipa yang ada belum dapat menjangkau daerah-daerah yang penduduknya tersebar secara tidak merata dan juga lokasinya tidak mudah dicapai karena berada pada lokasi pedalaman maupun perbukitan (Pemerintah Kabupaten Landak, Dinas Pekerjaan Umum dan Perumahan, 2016). Salah satu daerah yang belum memiliki 
fasilitas air bersih adalah di Kecamatan Mandor. Berdasarkan PERMEN-PUPR No 47/PRT/M/2015 Tentang Penggunaan Dana Alokasi Khusus Bidang Infrastruktur. Capaian Akses Air Minum Layak Tahun 2013 adalah Nasional 67,73\%, Perkotaan 79,34\%, dan Pedesaan 56,17\% dan Target Akses Aman Air Minum pada Tahun 2019 adalah 100\%

Masyarakat di Kecamatan Mandor dalam pemenuhan air bersih sehari-hari hanya mengandalkan air hujan, dan sumber mata air terdekat, namun jika pada musim kemarau kondisi mata air mengalami penurunan yang cukup besar, sehingga tidak bisa memenuhi kebutuhan akan air bersih. Seiring dengan bertambahnya jumlah penduduk, peningkatan kebutuhan air bersih juga terus meningkat. Sumber air baku di Kecamatan Mandor cukup banyak, salah satunya mata air yang berasal dari Bukit Godang. Sumbersumber air ini belum tereksplorasi untuk dimanfaatkan sebagai sumber air bersih hal ini dikarenakan akses yang terbatas menuju sumber-sumber air bersih tersebut. Untuk itu perlu dilakukannya suatu perancangan penyediaan air bersih agar masyarakat dapat memenuhi kebutuhan hidup.

\section{METODOLOGI PENELITIAN}

Penelitian ini merupakan suatu bentuk aplikasi penelitian lapangan dan pengembangan pemahaman mengenai perancangan teknik penyediaan air bersih bagi masyarakat dengan lokasi penelitian adalah Bukit Godang Tinggi yang secara administrasi masuk kedalam wilayah Desa Salatiga, Kecamatan Mandor. Hulu sumber air baku ini ada di Bukit Godang Tinggi. Aksesibilitas ke lokasi berupa jalan tanah, yang jika hujan akan licin dan berlumpur. Secara fisik, tanah di sekitar sumber air baku merupakan tanah liat berpasir. Mata air bukit godang berpotensi menjadi sumber air baku karena kurangnya aktifitas masyarakat di sekitar mata air tersebut, sehingga sumber air baku Bukit Godang dapat terbilang bebas dari pencemaran akibat kegiatan manusia. Secara kualitas, kuantitas, dan kontinuitas sumber air baku Bukit Godang masih perlu dilakukan penelitian.

Data yang digunakan untuk penelitian ini adalah data primer dan data sekunder. Data primer diperoleh saat melakukan survey lapangan, yang terdiri dari, data debit terukur di lapangan, data posisi global, data sampel air, dimensi penampang aliran, data letak posisi (node) jalur pipa. Sedangkan untuk data sekunder, diperoleh dari instansi terkait yang terdiri dari data kependudukan, data sosial ekonomi, data curah hujan, dan data klimatologi.

Analisis pengolahan data, digunakan aplikasi matematis, statistik untuk perhitungan proyeksi jumlah penduduk dan analisis kebutuhan air penduduk. Untuk analisis kuantitas air, dalam hal ini debit yang tersedia di sumber air baku, digunakan Metode Mock, sedangkan untuk perencanaan jalur pipa digunakan bantuan aplikasi komputer yaitu EPANET 2.0.

\section{HASIL DAN PEMBAHASAN}

\section{A. Hasil Survey Lapangan}

Hasil Survey Topografi

Dalam survey lapangan topografi, dilakukan peninjauan terhadap aksesibilitas sumber air baku, posisi air baku, dan jalur pipa transmisi, serta pendistribusiannya. Berikut adalah posisi sumber air baku dan elevasi sumber air baku hasil pengukuran lapangan; 
Tabel .1 Posisi Global Sumber Air Baku

\begin{tabular}{|c|c|c|c|c|c|}
\hline \multirow{2}{*}{ Kordinat } & \multicolumn{3}{|c|}{ Elevasi (m) } & \multicolumn{2}{c|}{ Jarak SAB Ke (km) } \\
\cline { 2 - 6 } & SAB & Desa & Kecamatan & Desa & Kecamatan \\
\hline $\begin{array}{c}0^{\circ} 20^{\prime} 21,9^{\prime \prime} \text { LU } \\
109^{\circ} 18^{\prime} 17,8^{\prime \prime} \mathrm{BT}\end{array}$ & 48 & 14 & 20 & 2,23 & 6,95 \\
\hline
\end{tabular}

Dari tabel tersebut dapat dilihat bahwa ada perbedaan elevasi antara sumber air baku dengan kecamatan dan desa adalah $34 \mathrm{~m}$. Menurut Petunjuk Teknis Pelaksanaan Prasarana Air Minum Sederhana (2007), jika beda tinggi sumber air baku dengan Desa melebihi 30 meter maka sistem pengalirannya baik menggunakan sistem gravitasi, sehingga metode pengaliran dalam perencanaan ini menggunakan sistem gravitasi. Dari data hasil survey topografi, juga diperoleh koordinat titik-titik yang digunakan sebagai input masukan paket program EPANET 2.0 guna perancangan jalur pipa dan untuk mengetahui apakah pada titik tersebut tekanan air akan berkurang.

\section{$>\quad$ Hasil Survey Hidrologi/Hidrometri}

Pengukuran hidrometri dilakukan untuk mendapatkan data kecepatan aliran dan data penampang aliran sumber air baku guna memperoleh gambaran besarnya volume air dalam aliran di sumber air baku pada waktu tertentu (debit $=\mathrm{Q}$ ). Pengukuran kecepatan aliran ( $v$ ) dilakukan dengan menggunakan currentmeter di titik yang kondisi alirannya agak tenang, tidak berkelok, dan tidak terlalu berbatu. Pengukuran dengan currentmeter ini dilakukan sebanyak tiga kali untuk mendapatkan hasil pengukuran yang akurat. Pengukuran dilakukan pada $1 / 4 \mathrm{~L}, 1 / 2 \mathrm{~L}$, dan $3 / 4 \mathrm{~L}$.

Lebar saluran (L) dan kedalaman ( $\mathrm{h}$ ) diukur mengunakan bantuan alat meteran, pita ukur, dan bak ukur untuk mendapatkan luas penampang basah (A). Dalam pengukuran hidrometri ini juga dilakukan pengukuran terhadap beberapa parameter kualitas air di lapangan, yakni suhu dan $\mathrm{pH}$. Selanjutnya dilakukan pengambilan sampel air untuk diuji di laboratorium uji guna mengetahui parameter kualitas air yang tidak dapat diukur di lapangan. Sampel air ini diambil sebanyak 1 botol dengan kapasitas $1.500 \mathrm{ml}$, sampel tersebut diawetkan dengan pengawetan fisika yaitu didinginkan didalam cooling box yang kemudian di bawa ke laboratorium penguji Dinas Kesehatan Provinsi Kalimantan Barat. Berikut adalah hasil survey hidrologi/hidrometri yang telah dilakukan;

Tabel 2. Hasil Survey Hidrologi/Hidrometri

\begin{tabular}{|c|c|c|c|c|c|c|c|c|c|c|c|}
\hline \multirow{2}{*}{ Desa } & \multirow{2}{*}{ Kecamatan } & \multirow{2}{*}{$\begin{array}{l}\mathrm{L} \\
(\mathrm{m})\end{array}$} & \multirow{2}{*}{$\begin{array}{c}h \\
(m)\end{array}$} & \multicolumn{3}{|c|}{$\begin{array}{c}v \\
\text { (m/20det) }\end{array}$} & \multirow{2}{*}{$\begin{array}{c}v \\
\text { Rata-rata } \\
\text { (m/det) }\end{array}$} & \multirow{2}{*}{$\begin{array}{c}A \\
\left(m^{2}\right)\end{array}$} & \multirow{2}{*}{$\begin{array}{c}Q \\
\left(m^{3} / d e t\right)\end{array}$} & \multirow{2}{*}{ pH } & \multirow{2}{*}{$\begin{array}{l}\text { Suhu } \\
{ }^{\circ} \mathrm{C}\end{array}$} \\
\hline & & & & $1 / 4 \mathrm{~L}$ & $1 / 2 \mathrm{~L}$ & $3 / 4 L$ & & & & & \\
\hline Salatiga & Mandor & 2,10 & 0,68 & 1,28 & 1,38 & 1,30 & 0,066 & 1,42 & 0,093 & 6 & 27 \\
\hline
\end{tabular}

Hasil perhitungan debit lapangan yang didapat akan digunakan sebagai kalibrasi dalam perhitungan debit bulanan untuk mendapatkan debit andalan.

B. Hasil Analisis

\section{Hasil Analisis Kebutuhan Air}

Analisis kebutuhan air dilakukan untuk memperkirakaan kebutuhan air penduduk di masa mendatang dengan cara memproyeksikan data jumlah penduduk selama 20 
tahun kedapan dengan beberapa metode proyeksi. Hasil analisis kebutuhan air yang meliputi kebutuhan air domestik dan non domestik dalam penelitian ini sebagai berikut;

Tabel 3 Total Kebutuhan Air Penduduk Desa

\begin{tabular}{|c|c|c|c|c|c|c|}
\hline \multirow{2}{*}{ URAIAN } & \multirow{2}{*}{ SATUAN } & \multicolumn{5}{|c|}{ TAHUN } \\
\hline & & 2017 & 2022 & 2027 & 2032 & 2037 \\
\hline 1 & 2 & 3 & 4 & 5 & 6 & 7 \\
\hline Kebutuhan Total & (liter/detik) & 4.0164 & 4.9475 & 6.4442 & 8.8801 & 12.6076 \\
\hline Kehilangan $20 \%$ & (liter/detik) & 3.2131 & 3.9580 & 5.1553 & 7.1041 & 10.0861 \\
\hline Total kebutuhan rata-rata & (liter/detik) & 7.2295 & 8.9055 & 11.5995 & 15.9841 & 22.6937 \\
\hline Total kebutuhan rata-rata & $\left(\mathrm{m}^{3} / \mathrm{dtk}\right)$ & 0.0072 & 0.0089 & 0.0116 & 0.0160 & 0.0227 \\
\hline Kebutuhan harian puncak (1,2x Qtot) & $(\operatorname{ltr} / \mathrm{dtk})$ & 7.9525 & 9.7961 & 12.7595 & 17.5826 & 24.9631 \\
\hline Kebutuhan harian puncak (1,2x Qtot) & $\left(\mathrm{m}^{3} / \mathrm{dtk}\right)$ & 0.0080 & 0.0098 & 0.0128 & 0.0176 & 0.0250 \\
\hline Kebutuhan jam puncak (1,5x Qtot) & $(\operatorname{ltr} / \mathrm{dtk})$ & 10.8443 & 13.3583 & 17.3993 & 23.9762 & 34.0406 \\
\hline Kebutuhan jam puncak (1,5x Qtot) & $\left(\mathrm{m}^{3} / \mathrm{dtk}\right)$ & 0.0108 & 0.0134 & 0.0174 & 0.0240 & 0.0340 \\
\hline
\end{tabular}

\section{Hasil Analisis Kualitas, Kuantitas, dan Kontinuitas Air}

\section{a. Hasil Analisis Kualitas Air}

Dari hasil analisis laboratorium dilakukan di laboratorium penguji Dinas Kesehatan Provinsi Kalimantan Barat, dengan acuan batas maksimum adalah PP R.I. No. 82 Tahun 2001 diketahui bahwa secara umum kualitas sumber air baku memenuhi kelas mutu air kelas 1, karena masih masuk dalam standar baku mutu yang diizinkan.

\section{b. Hasil Analisis Kuantitas Air}

Analisis kuantitas air dalam tugas akhir ini dilakukan dengan cara mengalihragamkan data curah hujan menjadi debit aliran. Hal ini dikarenakan tidak tersedianya data debit terukur dengan record panjang pada sumber air baku yang akan didesain. Pengalihragaman dilakukan dengan menggunakan Metode Mock.

Dalam menggunakan metode Mock, diperlukan data hujan dan hari hujan, luasan catchment area dan besarnya evapotranspirasi potensial. Dalam pekerjaan ini, besarnya evapotranspirasi potensial diperkirakan dengan menggunakan metode Penman Modifikasi FAO (1997).

Dari analisis yang dilakukan, diketahui debit andalan sumber air Bukit Godang sebagai berikut; 
Tabel 4 Resume Perhitungan Debit Andalan 80\%, 85\%, 90\% dan 99\% Sumber Air Baku Bukit Godang Tinggi

\begin{tabular}{|c|c|c|c|c|}
\hline \multirow{2}{*}{ Bulan } & \multicolumn{4}{|c|}{ Debit (lt/detik) } \\
\hline & $80 \%$ & $85 \%$ & $90 \%$ & $99 \%$ \\
\hline Jan & 750.15 & 414.63 & 53.24 & 15.14 \\
\hline Feb & 295.60 & 172.98 & 63.21 & 57.84 \\
\hline Mar & 460.24 & 352.30 & 159.09 & 30.55 \\
\hline Apr & 733.15 & 411.75 & 310.88 & 66.11 \\
\hline Mei & 711.51 & 282.31 & 201.61 & 74.06 \\
\hline Jun & 297.60 & 130.45 & 110.60 & 88.89 \\
\hline Jul & 232.78 & 61.50 & 25.95 & 14.84 \\
\hline Agust & 204.10 & 135.62 & 66.08 & 22.94 \\
\hline Sep & 256.86 & 155.63 & 17.04 & 14.66 \\
\hline Okt & 298.65 & 89.18 & 45.06 & 41.26 \\
\hline Nop & 1244.50 & 987.90 & 78.86 & 56.94 \\
\hline Des & 917.66 & 300.50 & 58.86 & 30.12 \\
\hline Rata-rata & $\mathbf{5 3 3 . 5 7}$ & 291.23 & 99.21 & 42.78 \\
\hline
\end{tabular}

\section{c. Hasil Analisis Kontinuitas Air}

Kontinuitas air pada sumber air baku dapat diperkirakan dengan membandingkan hasil analisis kebutuhan air penduduk (Tabel 3) dengan hasil analisis debit andalan 99\% (Tabel 4). Debit kebutuhan pada jam puncak ini, selanjutnya akan dikompilasi dengan hasil analisis perhitungan debit andalan sumber air baku Bukit Godang Tinggi yang ditinjau untuk melihat apakah sumber air baku ini dapat kontinu dan tersedia debitnya apabila dijadikan sebagai sumber air baku bagi penduduk. Hasilnya dapat dilihat pada tabel berikut;

Tabel 5. Hasil Analisis Kontinuitas Sumber Air Baku Bukit Godang Tinggi

\begin{tabular}{|c|c|c|c|}
\hline Lokasi & $\begin{array}{c}\text { Debit Andalan } \\
\mathbf{9 9 \%} \text { (It/detik) }\end{array}$ & $\begin{array}{c}\text { Kebutuhan Air Pada Jam } \\
\text { Puncak Tahun 2037 (It/detik) }\end{array}$ & $\begin{array}{c}\text { Kontinuitas Air } \\
\text { sampai Tahun } \\
\mathbf{2 0 3 7} \text { (It/detik) }\end{array}$ \\
\hline $\begin{array}{c}\text { Bukit Godang } \\
\text { Tinggi }\end{array}$ & 42,78 & 37,62 & 5,16 \\
\hline
\end{tabular}


Dari hasil analisis kontinuitas yang telah dilakukan, diketahui bahwa sumber air baku Bukit Godang Tinggi dapat digunakan sebagai sumber air baku apabila digunakan untuk melayani 3 Desa, yakni Desa Salatiga, Desa Simpang Kasturi dan Desa Mandor. Sumber air baku Bukit Godang Tinggi hanya digunakan untuk kebutuhan air bersih, sehingga tidak mengganggu penggunaan air untuk kebutuhan lainnya.

\section{d. Hasil Analisis Teknis Jaringan Pipa}

\section{Desain Broncaptering}

Broncaptering merupakan salah satu Sistem Instalasi Pengolahan Air Sederhana (SiPAS) yang digunakan dalam sistem penyediaan air minum pada unit produksi. Broncaptering berfungsi melindungi dan menangkap air dari mata air untuk ditampung dan disalurkan menggunakan pipa transmisi ke reservoir. Pemilihan jenis broncaptering yang direncanakan adalah berdasarkan Petunjuk Teknis Pelaksanaan Prasarana Air Minum Sederhana (2007) yaitu menggunakan broncaptering tipe I D (gravitasi kontak).

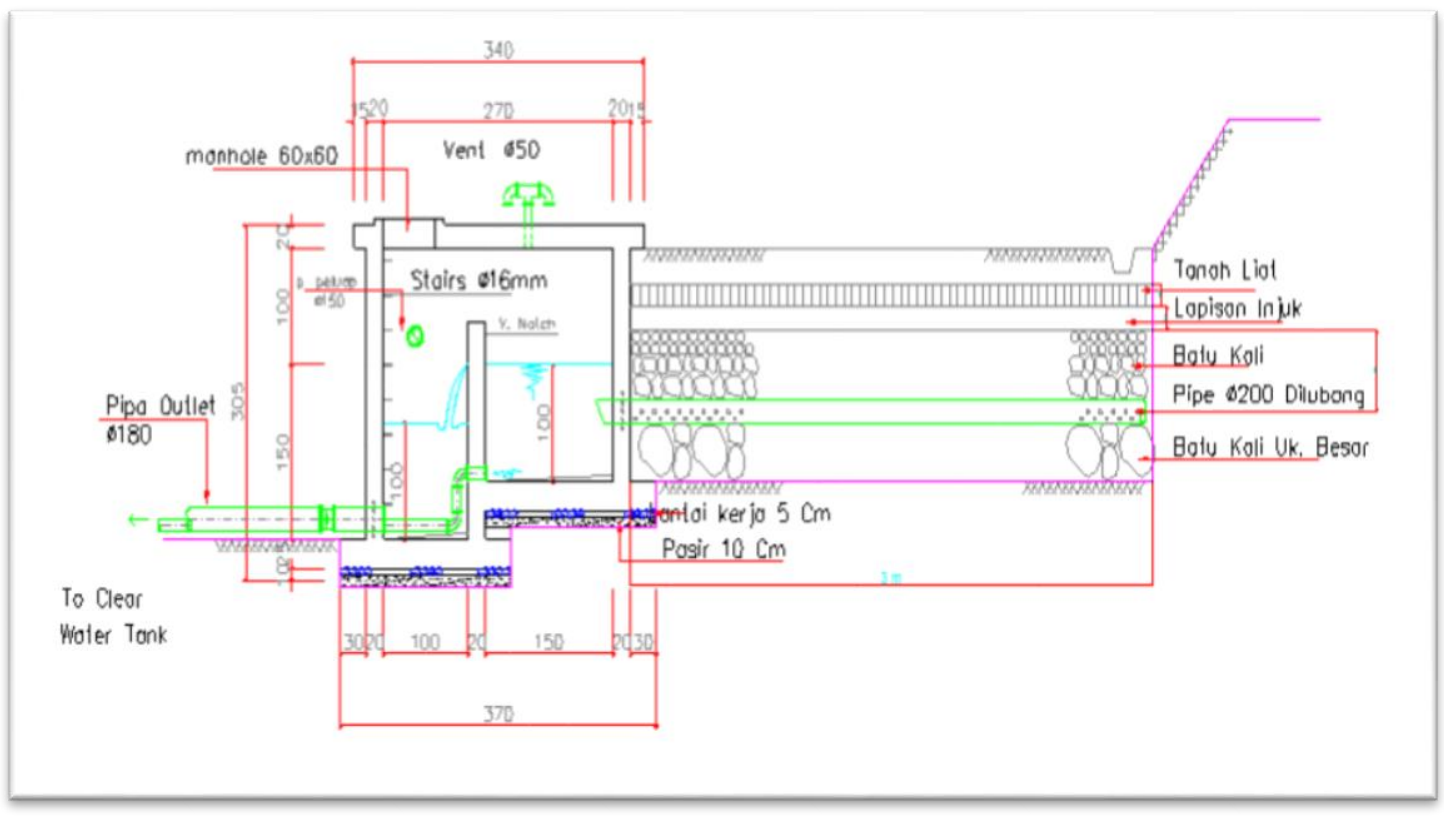

Gambar 1 Jenis Broncaptering Tipe I D (Gravitasi Kontak)

\section{Bak Penampung/Reservoir}

Reservoir merupakan bangunan yang terletak setelah proses penangkapan mata air menggunakan broncaptering. Reservoir berfungsi sebagai penampung dan penyeimbang tekanan air. Jarak antara reservoir dengan broncaptering adalah $2.233 \mathrm{~m}$ yang dihubungkan dengan pipa transmisi. Reservoir yang direncanakan dapat menyimpan cadangan sebesar $20 \%$ dari debit jam puncak sesuai sesuai kriteria perencanaan menurut NSPM Kimpraswil - Pedoman /Petunjuk Teknik Manual Bagian 6 Vol.II \& III Edisi Pertama (2002). Dari hasil analisis diketahui bahwa debit pada jam puncak sebesar 2.937.600 liter/hari, sehingga volume reservoir adalah $20 \% \times 2.937 .600=587.520$ liter/hari $=587,52 \approx 588 \mathrm{~m}^{3}$. Berdasarkan debit jam puncak, maka volume reservoir yang direncanakan sebanyak 1 (satu) buah. Dikarenakan ketersediaan lahan yang terbatas maka ditentukan kapasitas reservoir hanya menampung $50 \%$ dari volume total air pada jam puncak, dengan asumsi bahwa $50 \%$ nya lagi telah terpakai oleh masyarakat, maka volume reservoir yang direncana mampu menampung $326 \mathrm{~m}^{3}$, dengan $\mathrm{P} \times \mathrm{L} \times \mathrm{h}=14 \times 7 \times$ 3,4 . 


\section{E. Jaringan Pipa Transmisi}

Analisa jaringan pipa transmisi pada tugas akhir ini menggunakan perangkat lunak Epanet versi 2.0.

Dari hasil running program Epanet 2.0 didapatkan desain teknis seperti berikut:

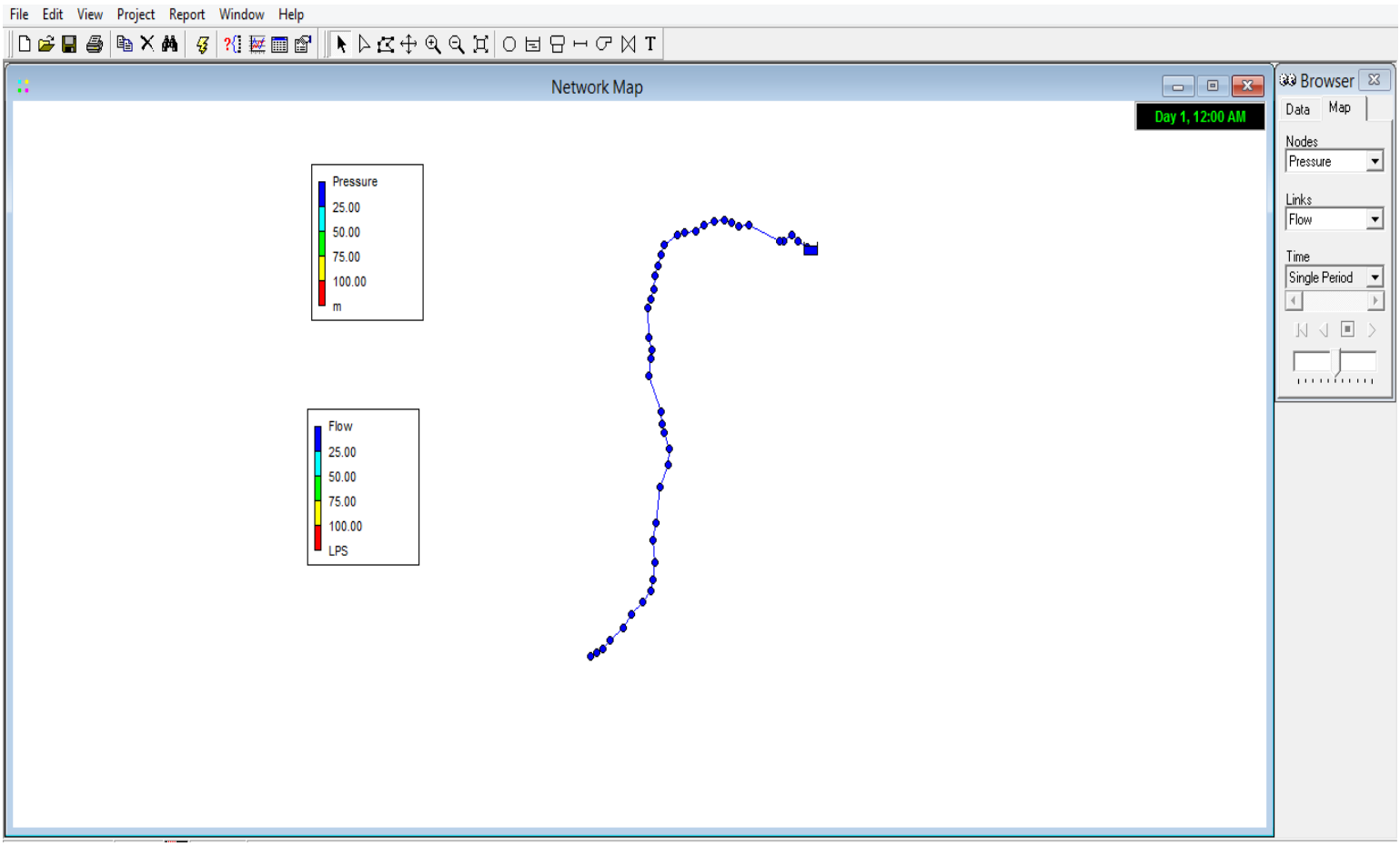

Gambar 2 Jaringan Pipa Transmisi pada pengoperasian EPANET 2.0

- Pipa transmisi menggunakan pipa HDPE dengan ukuran pipa sebagai berikut:

- Luas Penampang Pipa

$$
\begin{array}{ll}
A & =\frac{Q}{v}=\frac{0,0376 \mathrm{~m} 3 / \text { det }}{1,5 \mathrm{~m} / \text { det }}=0,025 \mathrm{~m}^{2} \\
A & =1 / 4 \pi \mathrm{D}^{2} \\
0,025 & =1 / 4 \pi \mathrm{D}^{2} \\
\mathrm{D} & =0.18 \mathrm{~m}=180 \mathrm{~mm}=7 \mathrm{inch}
\end{array}
$$

- Velocity (kecepatan pengaliran)

Menurut Permen PU No. 18/PRT/M/2007, kecepatan pengaliran air dalam pipa transmisi berkisar antara $0,3 \mathrm{~m} / \mathrm{dt}-6,0 \mathrm{~m} / \mathrm{dt}$. Hasil runing EPANET didapat velocity sebesar $1,5 \mathrm{~m} / \mathrm{dt}$ sehingga memenuhi syarat untuk kecepatan pengaliran pipa transmisi.

- Pressure (tekanan)

Menurut Rony (2017), sisa tekanan minimum adalah 1 bar atau 10 meter kolom air (mka), berlaku pada pipa sekunder atau tersier. Tekanan rata-rata sumber air Bukit Godang yaitu $12,82 \mathrm{~m}$, sehingga tekanan rata-rata memenuhi syarat batas minimum tekan. Pada beberapa titik seperti J1 dan J2 tidak mencapai 10 mka (dapat dilihat di lampiran), hal ini disebabkan karena titik tersebut merupakan titik awal penyaluran, jika tekanan di awal pipa terlalu tinggi akan dikhawatirkan pipa akan cepat rusak dan 
pecah. Sedangkan untuk sisa tekanan minimum diujung terjauh pada jalur pipa induk harus lebih besar dari 10 meter, hal ini telah sesuai karena tekanan pada titik terjauh sumber air baku Bukit Godang adalah 18,69 mka. Dikarenakan tekanan tidak mencapai 100 mka, maka tidak perlu diberikan bak pelepas tekan (BPT) hal ini sesuai dengan Petunjuk Teknis Pelaksanaan Prasarana Air Minum Sederhana (2007).

- Debit aliran dalam pipa transmisi air baku diperhitungkan berdasarkan kebutuhan jam puncak. Dari hasil perhitungan didapatkan besar debit adalah 37,6 liter/detik.

- Pipa HDPE dipilih pada perencanaan ini dengan alasan karena pipa HDPE adalah pilihan utama untuk instalasi air bersih. Pipa HDPE tersedia dari ukuran $20 \mathrm{~mm}$ sampai dengan $1200 \mathrm{~mm}$, pipa HDPE mempunyai tingkat fleksibelitas yang tinggi sehingga pipa HDPE bisa mengikuti struktur tanah. jika stuktur tanah berubah, maka pipa HDPE tidak akan putus.

\section{KESIMPULAN dan SARAN}

\section{A. Kesimpulan}

a. Dari hasil analisis, diketahui hasil analisis kuantitas sumber air bersih bukit godang memiliki debit aliran 42,78 liter/detik, hasil uji kualitas air baku di laboratorium memenuhi kelas mutu air kelas 1 berdasarkan PP RI 82 tahun 2001, dan kontinuitas air baku sampai tahun 2037 sebesar 5,16 liter/detik

b. Dari hasil analisis menggunakan EPANET 2.0, dapat diketahui bahwa air dari sumber air baku mata air Bukit Godang Tinggi apabila dialirkan untuk melayani Desa Salatiga masih dapat beroperasi dengan sistem gravitasi.

\section{B. Saran}

Saran-saran yang dapat diberikan dalam tugas akhir ini adalah sebagai berikut :

a. Perlu dilakukan penyelidikan tanah yang lebih mendalam untuk mengetahui daya dukung tanah terhadap bangunan-bangunan SPAM yang akan dibuat aman terhadap kemungkinan guling, geser ataupun gaya-gaya lain yang disebabkan oleh beban yang bekerja pada bangunan-bangunan SPAM tersebut.

b. Lingkungan di sekitar sumber air baku yang telah diteliti harus dapat terjaga sehingga dapat menjamin kelangsungan penyediaan air baik dari segi kualitas, kuantitas, maupun kontinuitas.

\section{UCAPAN TERIMA KASIH}

Puji Syukur kepada Allah Tritunggal Maha Kudus karena berkat rahmat dan kasihNya sehingga Skripsi ini dapat terselesaikan. Dalam penulisan Skripsi ini tidak lupa saya ucapkan terima kasih kepada dosen pembimbing skripsi saya, Ibu Laili Fitria dan Ibu Ulli Kadaria serta dosen penguji saya Bapak Arifin dan Ibu Suci Pramadita, serta saya ucapkan banyak terima kasih kepada kawan-kawan angkatan 2013 (STREAMYSTIK) yang telah banyak membantu dan terlebih khusus untuk kawan-kawan Teknik Lingkungan 2013 yang telah berjuang untuk belajar sama-sama baik yang sudah menjadi alumni maupun yang sedang berjuang untuk menyelesaikan studi semoga selalu diberikan semangat dan tidak diberikan halangan untuk segala kegiataannya. Semoga penelitian ini dapat bermanfaat bagi semua pihak. 


\section{DAFTAR PUSTAKA}

Al-Layla, M.Anis Shamim Ahmad, and E.Joe Middebrooks. 1978. Water Suplay Engineering Design. Ann Arbor Science Publishers Inc. Michigan. USA.

Alsa, Asmadi. 2007. Pendekatan Kuantitatif dan Kualitatif Serta Kombinasinya dalam Penelitian Psikologi. Pustaka Pelajar. Yogyakarta.

BPS Kabupaten Landak. 2016. Kecamatan Mandor Dalam Angka. Ngabang.

Soemarto. C. D. 1999. Hidrologi Teknik, Penerbit Erlangga, Jakarta.

Chandra, B. (2007). Pengantar Kesehatan Lingkungan. Penerbit Buku. Kedokteran EGC. Hal. 39, 42. Jakarta.

Effendi, H. 2003. Telaah Kualitas Air bagi Pengelolaan Sumber Daya dan Lingkungan Perairan. Cetakan Kelima. Yogjakarta. Kanisius

Hajia, Muhammad Chaiddir. 2015. Perencanaan Sistem Penyediaan Air Bersih di Desa Taratara Kecamatan Tomohon Barat. Universitas Sam Ratulangi Fakultas Teknik Jurusan Teknik Sipil. Manado.

Joko, Tri. 2010. Unit Air Baku dalam Sistem Penyediaan Air Minum. Edisi Pertama Yogyakarta; Graha IImu. 2010. ISBN : 978-979-756-596-1.

Rosadi. M. I. 2011, Perencanaan Pengembangan Sistem Jaringan Distribusi PDAM IKK Durenan Kabupaten Trenggalek, Program Studi D-4 Teknik Perancangan Prasarana Lingkungan Permukiman Fakultas Teknik Sipil Dan Perencanaan Institut Teknologi Sepuluh Nopember. Surabaya.

Mock, F.J, 1973, Land Capability Appraisal Indonesia, Water Availability Appraisal, UNDP/FAO, Bogor.

Montieth, J. L.1965. "Evaporation and Environment." 19th Symposium of the Society for Experimental Biology: 205-234. Cambridge Univ. Press, Cambridge.

Notoatmodjo,S.2002. Metodologi Penelitian Kesehatan. Rineka Cipta. Jakarta.

NSPM KIMPRASWIL. Pedoman/Petunjuk dan Manual Air Minum Perkotaan. Edisi Pertama, Desember 2002. Bagian 6 (Volume I) : 84

NSPM KIMPRASWIL. Pedoman/Petunjuk Dan Manual Air Minum Perkotaan. Edisi Pertama, Desember 2002.Bagian 6 (Volume II dan III) : 24

Pemerintah Republik Indonesia, 2001. Peraturan Pemerintah Nomor 82 tahun 2001 Tentang Pengelolaan Kualitas Air dan Pengendalian Pencemaran Air, Jakarta

Pemerintah Kabupaten Landak, Dinas Pekerjaan Umum dan Perumahan, 2016 Pembuatan DED SPAM IKK Mandor, Ngabang

Peraturan Menteri Pekerjaan Umum dan Perumahan Rakyat Republik Indonesia Nomor 47/Prt/M/2015 Tentang Petunjuk Teknis Penggunaan Dana Alokasi Khusus Bidang Infrastruktur

Peraturan Menteri Pekerjaan Umum dan Perumahan Rakyat Republik Indonesia Nomor 27/Prt/M/2016 Tentang Penyelenggaraan Sistem Penyediaan Air Minum

Peraturan Menteri Pekerjaan Umum Nomor : 18/Prt/M/2007 Tentang Penyelenggaraan Pengembangan Sistem Penyediaan Air Minum 
Rony Riduan, Muhammad Firmansyah, dan Shelda Fadhilah, 2017. Evaluasi Tekanan Jaringan Distribusi Zona Air Minum Prima (ZAMP) PDAM Intan Banjar Menggunakan EPANET 2.0. Program Studi Teknik Lingkungan, Fakultas Teknik, Universitas Lambung Mangkurat, Banjarbaru

SNI 06 - 4829 - 2005/ ISO 4427:2007, Pipa HDPE

SNI 6989.57:2008, Metoda pengambilan contoh Air Permukaan.

Soewarno, 2000, Hidrologi Operasional Jilid Kesatu, Penerbit PT. Aditya Bakti, Bandung. 